\title{
Microwave Induced Carbon from Waste Palm Kernel Shell Activated by Phosphoric Acid
}

\author{
Abdul Rahim Yacob, Noramirah Wahab, Nurshaira Haifa Suhaimi, and Mohd Khairul Asyraf Amat \\ Mustajab
}

\begin{abstract}
Activated carbon has been known as an excellent adsorbent which has been widely used due for its large adsorption capacity and low cost. In Malaysia, palm kernel shell is one of the main agriculture wastes obtained from palm oil industries. In this study, the palm kernel shell-based activated carbon was prepared via microwave-induced activation process using phosphoric acid, $\mathrm{H}_{3} \mathrm{PO}_{4}$ at difference concentration as the activating agent. Home modified microwave with power $350 \mathrm{~W}$ was used for activation process of $1 \mathrm{~min}$ on and $1 \mathrm{~min}$ off. The activation process took place for 10 minutes $(5$ cycles). This prepared activated carbon samples were chemical characterized using Fourier Transform Infrared (FTIR), Nitrogen Gas Adsorption analysis and thermal analysis. The results obtained indicate that microwave induced activated carbon can be prepared in the presence of a chemical activation agent for in this case, phosphoric acid. This study shows, activated carbon at $60 \%$ phosphoric acid concentration has the highest surface area of $630 \mathrm{~m}^{2} / \mathrm{g}$. The production of activated carbon from agricultural waste such as palm kernel shells via microwave induced can be a new promising method in producing easier and simpler high surface area activated carbon.
\end{abstract}

Index Terms-Activated carbon, palm kernel shells, microwave-induced, phosphoric acid.

\section{INTRODUCTION}

Activated carbons are an extremely versatile, carbonaceous material with high surface area and can be develop into various porosity and used for applications such as for industrial wastewater and gas treatment. The precursor for production of activated carbon, from utilization of agricultural and forestry product has increase in recent years because of their abundance, availability and low price [1]. Due to their excellent adsorption capability, it is widely used for commercial and in industries. The high adsorptive capacity of activated carbon is associated with its internal porosity and others properties such as surface area, pore volume and pore size distribution. The process of activated carbon production begins with the selection of a raw carbon source, which normally comes from agriculture and industrial waste. The most common raw sources are wood,

Manuscript received June 15, 2012; revised October 25, 2012. This work was supported in part by the Universiti Teknologi Malaysia, Ministry of Higher Education and Ministry of Science, Technology and Innovation Malaysia through research facilities and grants.

A. R. Yacob is with the Universiti Teknologi Malaysia, Johor Bahru, Johor 81310 Malaysia (e-mail: manrahim@kimia.fs.utm.my).

N. Wahab, N. H. Suhaimi, and M. K. A. A. Mustajab are with the Department of Chemistry, Faculty of Science, Universiti Teknologi Malaysia, Johor Bahru, Johor 81310 Malaysia (e-mail: noramirah89@gmail.com, shaafaa.hairaa@gmail.com, krulchubby84@yahoo.com). sawdust, lignite, peat, coal, coconut shells, and petroleum residues [2]. They can be treated and developed to be a new product and in turn can reduce environmental pollution.

In the last few decades, development on microwave equipments and usage has grown rapidly. Microwave-induced nowadays is a new technique which finds other application in the areas of material sciences, food processing, telecommunication, analytical science, wood drying, plastic and rubber treatment [3]. To date, microwave energy has been widely used in several fields of applications on both research and industrial processes. In particular, microwave heating or induce can arise from direct interaction of matter with electromagnetic energy. Vast interest in materials science and processing have offers a number of potential advantages over conventional heating. The main advantage of using microwave is that the treatment time can be considerably reduced and economical. In many cases, it represents a reduction in the energy consumption and green chemistry. The previous study, microwave energy is derived from electrical energy with a conversion efficiency of approximately $50 \%$ for $2450 \mathrm{MHz}$ and $85 \%$ for $915 \mathrm{MHz}$ respectively [3].

\section{PROCEDURE FOR PAPER SUBMISSION}

\section{A. Materials}

The materials, palm kernel shells were used for the preparation of activated carbon were obtained from Palm Oil Mill Industry. Phosphoric Acid $\left(\mathrm{H}_{3} \mathrm{PO}_{4}\right) \quad 85 \%$ and Hydrocloric Acid $(\mathrm{HCl})$ were purchased from Merck. Nitrogen gas was supplied by Malaysian Oxygen Bhd.

\section{B. Preparation of Activated Carbon}

The first step in preparation of activated carbon is the cleaning process. In this process, $50 \mathrm{~g}$ of dried palm kernel shell (PKS) was soaked with $500 \mathrm{~mL}$ of hydrochloric acid, HCI $1 \mathrm{M}$ in a $1 \mathrm{~L}$ beaker. The soaked mixture was left overnight. The purpose of soaking is to remove impurities. After that, the samples was thoroughly washed with hot distilled water until reached $\mathrm{pH} 7$ and immediately dried under sunlight to eliminate moisture.

Then, $7.0 \mathrm{~mL}$ of various concentration of phosphoric acid in a range of $10-80 \%$ was added into $3.0 \mathrm{~g}$ of palm kernel shells in a small beaker and left at room temperature for 48 hours. All the samples were labeled as AC-10 \% - AC-80\% respectively according to the concentrations.

These samples were then placed in a microwave (Fig. 1) with inducing procedure of 1 minute on and 1 minute off. The process of inducing was allowed for 10 minutes (5 cycles). The setup of modified microwave is as shown in Fig. 1 and to 
minimized contamination and forming of oxides, nitrogen gas was allowed to flow. When the process of activation completed, the prepared activated carbon were then cleaned. The washing process was repeated until reaches $\mathrm{pH} 7$.

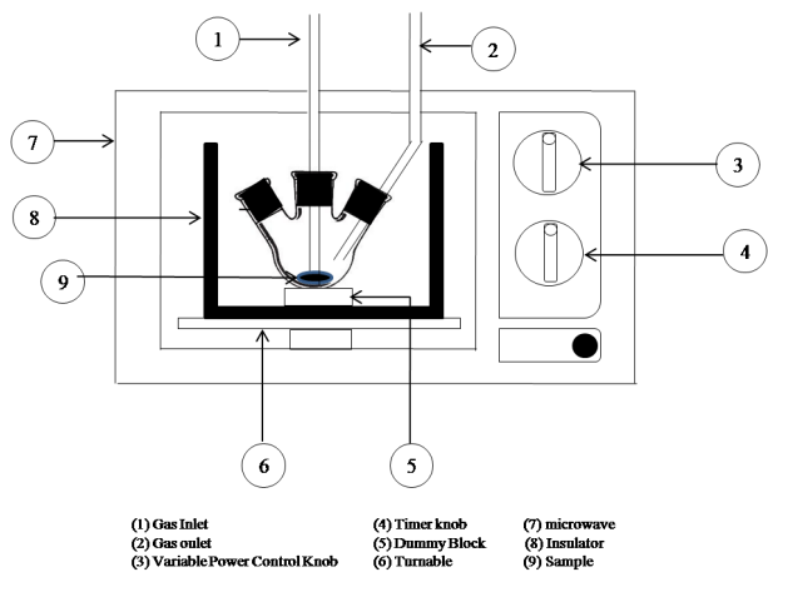

Fig. 1. The schematic diagram of modified microwave oven

\section{Characterization}

Characterization of activated carbon was done by Fourier Transform Infrared Spectrophotometer (FTIR), Single Point BET analysis and Thermal Analysis. The pore structure characterization were determined by Nitrogen Gas Adsorption Analysis at $77 \mathrm{~K}$ using Micromeritics Pulse Chemisorb 2705 and Micromeritics ASAP 2010. The weight loss analysis via thermal analysis was determined using Carbolite furnace and analytical balance .

\section{RESUlTS AND DisCUSSIONS}

\section{A. Effect of Weight Loss against Temperature}

The temperature effect on the prepared activated carbon was examined using thermal analysis. In this study, thermal analysis was carried out in order to determine the thermal stability of raw palm kernel shell and prepared activated carbon samples. There are two samples: raw-PKS and AC-60\% were subjected to measure in temperature range of $0-800^{\circ} \mathrm{C}$ under air flow. The TG curves for raw-PKS and AC-60\% are shown in Fig. 2. Raw-PKS exhibits a significant weight loss of the sample. In the first activation temperature, $300^{\circ} \mathrm{C}$ the weight loss was $0.5782 \mathrm{~g}$ which decreases strongly. This presents $19.15 \%$ of weight loss and most probably due to evaporation of surface and bonded water molecules. This is an agreement with Mercedes et al., which stated the increase in percentage weight loss is commonly caused by the thermodesorption of physically adsorbed materials such as water [4].

At the temperature of $400^{\circ} \mathrm{C}$, a major weight loss of about $64.22 \%$ was observed. Such weight loss is probably attributed to the decomposition or oxidation of the volatile organic compound (VOC) in the palm shells. Further increase in temperature causes the percentage weight loss of raw-PKS to decrease gradually. This is probably due to the higher VOC and carbon residue. This experiment is repeated for palm kernel shells which were activated with $60 \%$ phosphoric acid, labeled AC-60\%. The same pattern is observed except the higher weight VOC and carbon residue is removed after $500^{\circ} \mathrm{C}$. There are no significant changes after this temperature. It is believed that the organic compounds in raw-PKS were oxidized completely at $500^{\circ} \mathrm{C}$, which is typical of lignocellulosic materials [5]. This experiment further proved the capability of phosphoric acid to penetrate deeper into the carbon shell structure creating cavity and pores, thus increase in the surface area.

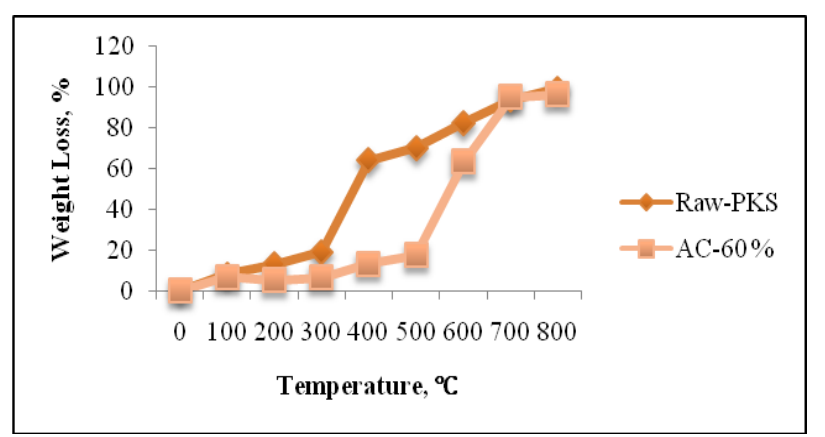

Fig. 2. Percentage weight loss against temperature of raw-PKS and AC-60\%

\section{B. Fourier Transform Infrared Spectroscopy (FTIR)}

Fig. 3 shows the FTIR spectra of raw palm kernel shell and the prepared microwave induced activated carbons impregnated in $10 \%$ to $80 \%$ phosphoric acid concentration. It can be seen that only raw PKS shows the most complicated and apparent spectrum. FTIR spectrum of raw-PKS shows many peaks belonging to different functional groups. A strong and broad adsorption peak appeared at $3446.62 \mathrm{~cm}^{-1}$ related to hydroxyl group. The band located at $2922.01 \mathrm{~cm}^{-1}$ corresponded to the $\mathrm{C}-\mathrm{H} \mathrm{sp}{ }^{3}$ stretching in the methyl groups. Another peak is observed at $1738.21 \mathrm{~cm}^{-1}$ which represents the stretching of $(\mathrm{C}=\mathrm{O})$ carbonyl groups. The raw-PKS spectrum also reveals a band at $1629.22 \mathrm{~cm}^{-1}$ corresponding to the stretching of $\mathrm{C}=\mathrm{C}$ in aromatic compounds. A peak at $1245.57 \mathrm{~cm}^{-1}$ and a subsequent small rise at $1019.47 \mathrm{~cm}^{-1}$ could be assigned to the stretching of $\mathrm{C}-\mathrm{O}$ in esters, ethers or phenol groups. From the analysis, it can be suggested that the main oxygen groups present in the raw-PKS are carbonyl groups, ethers, esters, alcohols and the phenol groups. Furthermore, the raw-PKS samples contain a lot of elements and impurities before undergoing the activation process.

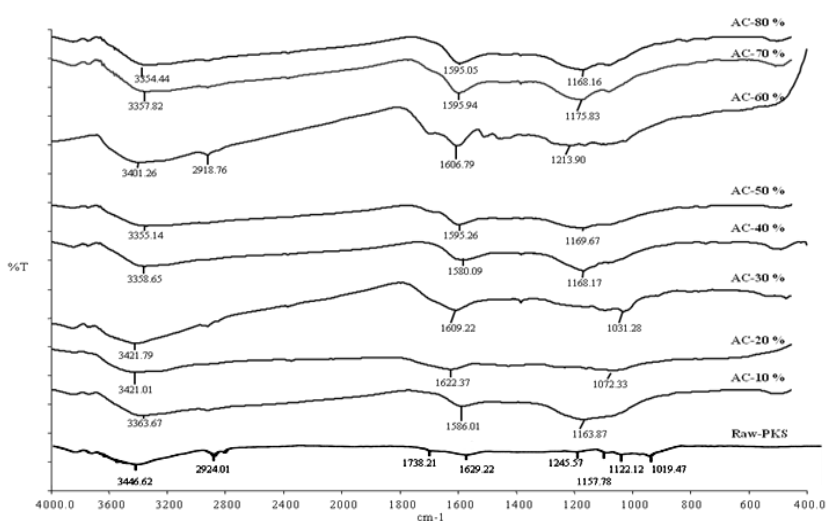

Fig. 3. The FTIR spectrum for Raw-PKS and activated carbon with different concentration

Unlike the spectrum showed by raw-PKS, spectra of all prepared activated carbon, AC- $10 \%$ to $\mathrm{AC}-80 \%$ indicated the reduction in absorption peaks of functional groups as the 
concentration increase. The similarity of the chemical activated carbon displayed by FTIR spectrum is shown in Fig. 3. The most significant absorption peak which indicates the presence of $\mathrm{C}=\mathrm{C}$ aromatic carbon were observed at the absorption around $1580.09 \mathrm{~cm}^{-1}$ to $1622.37 \mathrm{~cm}^{-1}$ respectively. This absorption illustrates the presence of active carbon in all the prepared samples. This further proves that the presence of active carbon might be obtained during carbonization process using the modified microwave method. The functional groups were successfully removed, as the volatile compounds (VOC). The $\mathrm{C}=\mathrm{C}$ stretching appear at all microwave induced activated carbon, thus indicated that all the prepared samples have successfully converted to activated carbon most probably in graphite morphology.

\section{Nitrogen Gas Adsorption Analysis}

\section{1) BET surface area}

Initially, the surface area of raw PKS was only $\sim 1 \mathrm{~m}^{2} / \mathrm{g}$. By microwave induced and assisted by various concentration phosphoric acids, the surface area of the activated carbon was increased drastically. Fig. 3, shows that all the activated carbon gave extensively higher BET surface area as compared to raw PKS. The AC-60\% achieved the highest surface area of $630 \mathrm{~m}^{2} / \mathrm{g}$ compared to other acid Iconcentrations. As the $\mathrm{H} 3 \mathrm{PO} 4$ concentration increased, it is expected more potential site could be penetrated and occupied by the activating agent who causes the pore opening, widening whilst removing the heavier VOC. This result is in agreement to earlier TG/TGA experiments.

In the excess of H3PO4 concentration, however decrease in surface area is observed. This is most probably due to the collapsed of the carbon structure or development of insulating layers [4]. The whole surface area pattern is displayed, shown by Fig. 4 .

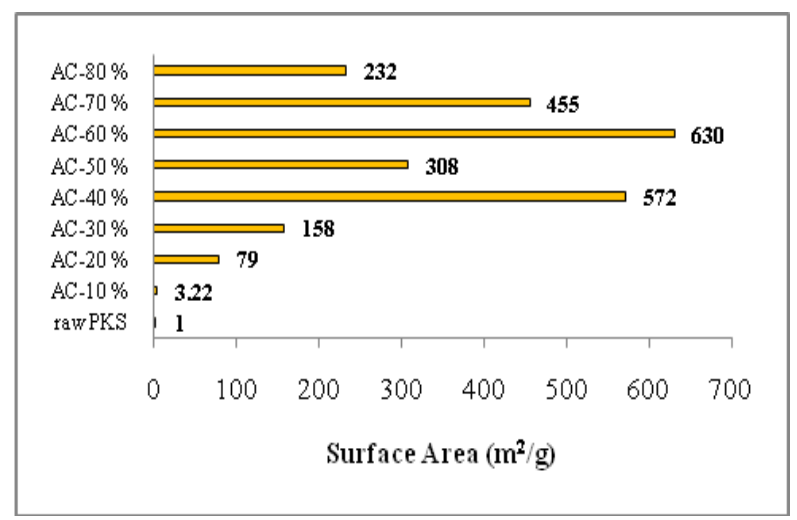

Fig. 4. BET surface area of raw-PKS and prepared activated carbons

\section{2) Isotherm plot}

AC-50\% and AC-60\% were selected to study their isotherm plots and pore size distribution in order to see clear picture about these samples. Fig. 5 and 6 shows isotherm plot for $\mathrm{AC}-50 \%$ and $\mathrm{AC}-60 \%$ respectively.

As shown in Fig. 5, this isotherm plot was classified as Type IV isotherm because low intake of nitrogen gas occurred at starting point and hysteresis loop appeared at the isotherm at relative pressures above 0.4 caused by capillary condensation [6-8]. This isotherm proved that the prepared $\mathrm{AC}-50 \%$ had mesoporous pore, thus low surface area recorded for this sample at Fig. 4.

Fig. 6 indicated two types of adsorption-desorption isotherm for $\mathrm{AC}-60 \%$, contrasted with $\mathrm{AC}-50 \%$. The high intake of nitrogen gas at low relative pressure was referring to Type 1 and presence of hysteresis loop at middle of isotherm plot can be classified as Type IV isotherm [7]. These observable facts clearly proved that AC-60\% had mixture of microporous and mesoporous structure which generally had surface area around 500 to $1500 \mathrm{~m}^{2} / \mathrm{g}$ [9-10].

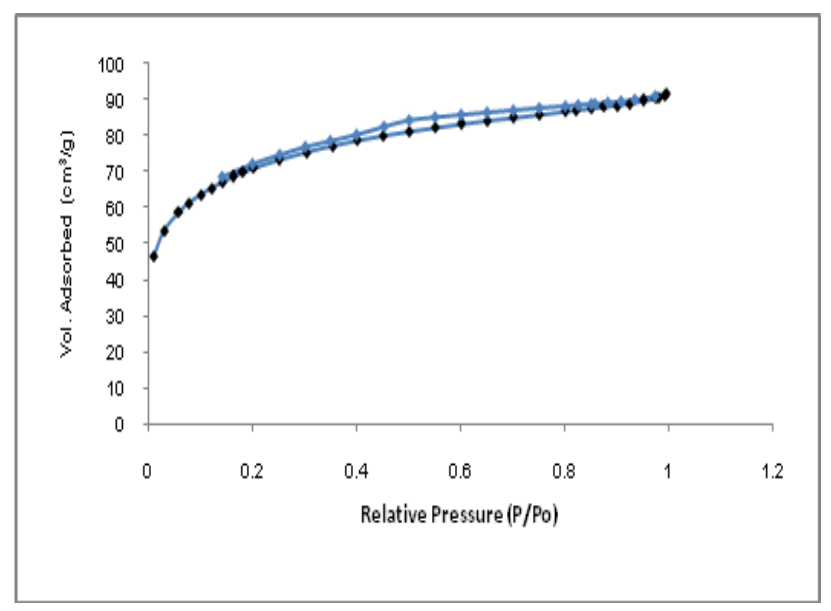

Fig. 5. Isotherm plot for AC-50\%

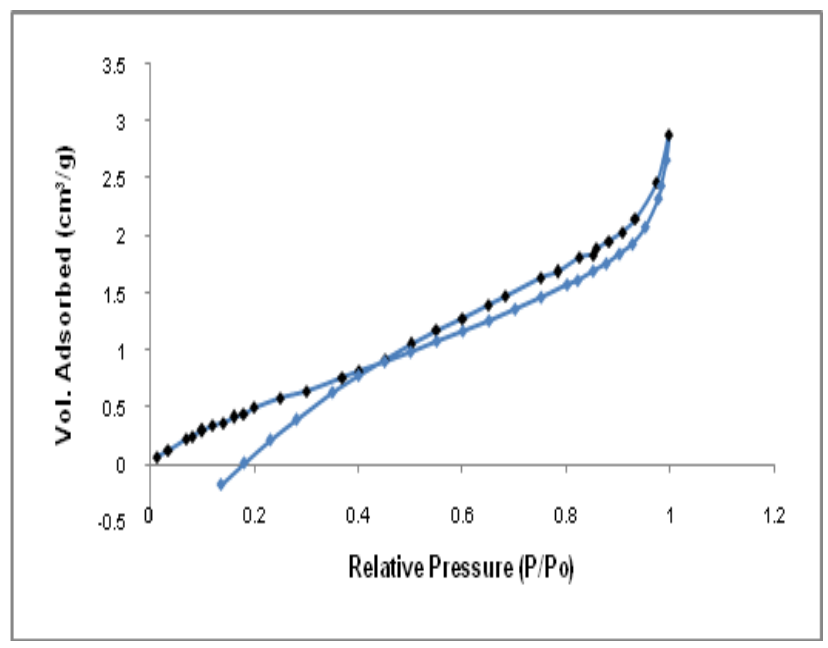

Fig. 6. Isotherm plot for AC-50\%

\section{3) Pore Size Distribution.}

This analysis is done to determine range of pore size at the sample using BJH method. Fig. 7 and 8 illustrate pore size distribution plot for AC-50\% and AC-60\% respectively. Fig. 7 indicates pore size for AC-50\% and was allocated majorly at range 80 to $100 \AA$, whilst minor distribution occurred at 30 to $50 \AA$. This distribution showed that AC-50\% is mostly in mesoporous structure, supported by their isotherm plot (Fig. 5).

In contrast, major distribution pore for $\mathrm{AC}-60 \%$ at range 10 to $30 \AA$ and only small area of distribution at higher range (> $40 \AA$ ) illustrated at Fig. 8. The recorded data proved that AC- $60 \%$ contained mixture of microporous and mesoporous structure of pore as firstly demonstrated by their isotherm plot (Fig. 6). In addition, usage of $60 \% \mathrm{H}_{3} \mathrm{PO}_{4}$ has catalyzed the formation of smaller internal pores inside the prepared external pore which exhibit higher surface area as compared to $50 \% \mathrm{H} 3 \mathrm{PO} 4$. This data again was proved the BET surface area result earlier in this section. 


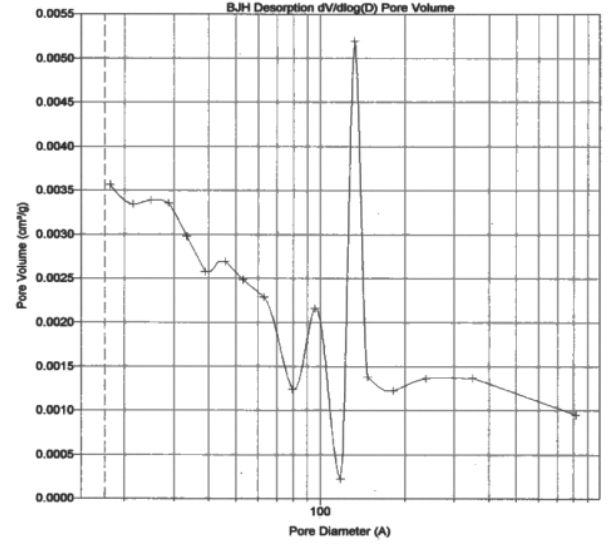

Fig. 7. Pore distribution plot for AC-50\%

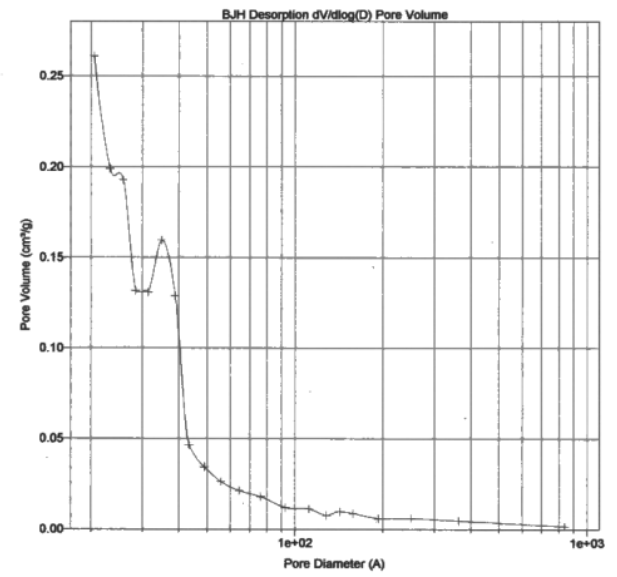

Fig. 8. Pore distribution plot for AC-60\%

\section{CONCLUSION}

In this study, microwave-induced high surface area, chemical activated carbon has been successfully prepared using waste palm kernel shells. It was chemical characterized using Fourier Transform Infrared Spectroscopy (FTIR), Nitrogen Gas Adsorption analysis and Thermal Analysis respectively. The result obtained from the chemical characterization ascribe that the type and concentration activation process influenced the chemical and physical properties of activated carbon. It can be induced that the microwave activated carbon with $60 \%$ concentration of phosphoric acid used gives the best prepared activated carbon with $630 \mathrm{~m}^{2} / \mathrm{g}$ surface area compared to the others. In conclusion, the microwave induced method is a potential alternative and simpler method in producing activated carbon from agriculture waste.

\section{ACKNOWLEDGMENT}

The author would like to thank UTM, Ministry of Higher Education and Ministry of Science, Innovation and Technology Malaysia for the research grants that makes this work possible.

\section{REFERENCES}

[1] S. Timur, I. C. Kantarli, S. Onenc, and J. Yanik, "Characterization an application of activated carbon produced from oak cups pulp valex residue," J. Anal. Appl. Pyrolysis, vol. 1, pp. 1-39, 2010.

[2] E. Yagmur, M. Ozmak, and Z. Aktas, "A novel method for production of activated carbon from waste tea by chemical activation with microwave energy," Fuel, vol. 87, pp. 3278-3285, 2008.
[3] F. K. Yuen and B. H. Hameed, "Recent developments in the preparation and regeneration of activated carbons by microwaves," Advanced in Colloids and Interfaces Science, vol. 149, pp. 21-26, 2009.

[4] S. Z. Hanapi, A. R. Yacob, and N. I. Masrom, "Tungsten carbide synthesis by microwave-induced alloying using phosphoric acid activated palm kernel shell carbon," Journal of Material Science and Engineering, vol. 4, no. 12, pp. 68-73, 2010.

[5] M. M. M. Valer, I. Dranca, T. Lupascu, and R. Nastas, "Effect of adsorbate polarity on thermodesorption profiles from oxidized and metal-impregnated activated carbons," Carbon, vol. 42, pp. 2655-2659, 2004.

[6] Z. Ryu, J. Zheng, M. Wang, and B. Zhang, "Characterization of pore size distribution on carbonaceous adsorbents by DFT," Carbon, vol. 37, no. 8, pp. 1257-1264, 1999.

[7] G. Gong, Q. Xie, , Y. Zheng, S. Ye, and Y. Chen, "Regulations of pore size distribution in coal-based activated carbon," New Carbon Materials, vol. 24, no. 2, pp. 141-146, 2009.

[8] E. K. Putra, R. Pranowo, J. Sunarso, N. Indraswati, and S. Ismadji. "Performance of Activated Carbon and Bentonite for Adsorption of Amoxicillin from Wastewater: Mechanisms, Isotherms and Kinectics," Water Research, vol. 43, pp. 2419-2430. 2009.

[9] N. M. Mustapha, A. R. Yacob, and H. M. Al Swaidan. "Elemental and Physical Effect of Carbon from Date's Frond after Activation by Phosphoric Acid," J Materials Science and Engineering, vol. 5, no. 1, pp. 20-25, 2011.

[10] A. R. Yacob, N. M. Mustapha, M. K. A. A. Mustajab and H. M. Al Swaidan, "Physical Activation of Saudi Arabia Date Palm Tree's Foliar, Frond and Thorn," in Proceeding of MIMT 2010, pp. 511-517.

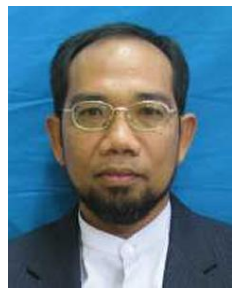

Abd Rahim Yacob was born at Shah Alam, Selangor. He received his first Bachelor degree in Chemistry at USM. After that, he firstly worked at Chemistry Department of Malaysia, one of government agencies under Ministry of Science, Technology and Innovation, Malaysia for almost 10 years. After that, he was pursuing his academic qualification for both Master and Doctor of Philosophy at Cardiff University, United Kingdom, major in Physical Chemistry. To date, he is one of Professor at Chemistry Department, Faculty of Science, Universiti Teknologi Malaysia. His passion are in physical chemistry, material science, catalyst's application and forensic areas and to date, he was successfully published about 70 papers in various international journals, conferences and successfully produced three academics books. He also was received seven research grants from various agencies to support his research activities.

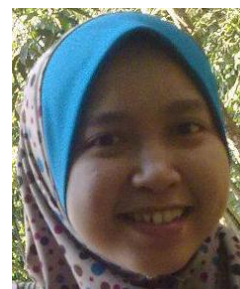

Noramirah Wahab has successfully obtained her Bachelor degree in Industrial Chemistry from Universiti Teknologi Malaysia in 2010. She joined research group under supervision Prof. Dr. Abd. Rahim Yacob and completing her Final Year Project focused on preparation of activated carbon using microwave heating. Now, she is working as R\&D executive at $\mathrm{HDI}, \mathrm{OKH}$.

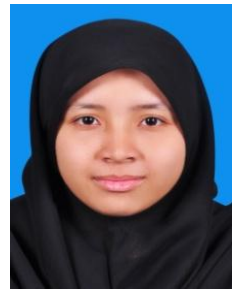

Nurshaira Haifa Suhaimi was born at Kota Bahru, Kelantan. She managed to obtain his B.S.c in Chemistry from Universiti Teknologi Malaysia, in 2010. Now, she is pursuing her Master degree in physical chemistry area, towards preparation of activated carbon and molybdenum carbide using microwave assisted methods. Her interest are in catalyst preparation and application, material science and nanotechnology area.

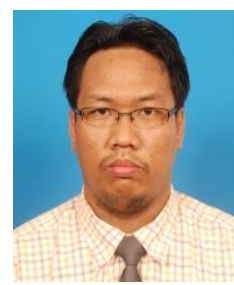

Mohd Khairul Asyraf Amat Mustajab was born at Petaling Jaya, Selangor. He received his B.Sc in Industrial Chemistry from Universiti Teknologi Malaysia, in 2007. He firstly joined Prof. Dr. Abd. Rahim Yacob's research group as Research Assistant and successfully received his Master degree in 2010. Now, he is pursuing his Doctor of Philosophy level in molybdenum carbide preparation and its catalytic activity in carbon dioxide hydrogenation. Catalys preparation and application, physical chemistry, nanotechnology and material science area are his major interest. 